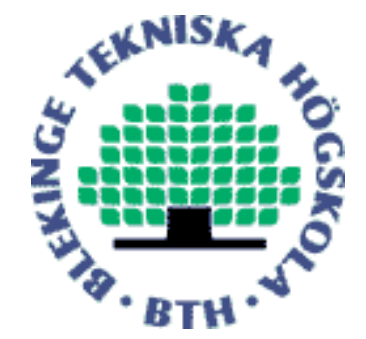

Copyright (C) 2013 IEEE.

Citation for the published paper:

Analytics for Product Planning: In-depth Interview Study with SaaS Product Managers

Farnaz Fotrousi, Katayoun Izadyan, Samuel Fricker

IEEE Cloud

2013 Santa Clara, CA, USA

This material is posted here with permission of the IEEE. Such permission of the IEEE does not in any way imply IEEE endorsement of any of BTH's products or services Internal or personal use of this material is permitted. However, permission to reprint/republish this material for advertising or promotional purposes or for creating new collective works for resale or redistribution must be obtained from the IEEE by sending a blank email message to pubs-permissions@iee.org.

By choosing to view this document, you agree to all provisions of the copyright laws protecting it. 


\section{Analytics for Product Planning: In-depth Interview Study with SaaS Product Managers}

\author{
Farnaz Fotrousi \\ School of Computing \\ Blekinge Institute of Technology \\ Karlskrona, Sweden \\ farnaz.fotrousi@bth.se
}

\author{
Katayoun Izadyan \\ Karlskrona, Sweden \\ kaia10@student.bth.se
}

\author{
Samuel A. Fricker \\ School of Computing \\ Blekinge Institute of Technology \\ Karlskrona, Sweden \\ samuel.fricker@bth.se
}

\begin{abstract}
SaaS cloud computing, in contrast to packaged products, enables permanent contact between users of a software product and the product-owning company. When planning the development and evolution of a software product, a product manager depends on reliable information about feature attractiveness. So far, planning decisions were based on stakeholder opinion and the customer's willingness to buy. Whether or not a feature actually is used was out of consideration. Analytics that measure the interaction between users and the SaaS gives product managers unprecedented access to information about product usage. To understand whether and how SaaS analytics can be used for product planning decision, we performed 17 in-depth interviews with experienced managers of SaaS products and analyzed the results analyzed with a mixed-method strategy. The empirical results characterize the relevance of a broad range of analytics for product planning decisions, and the strengths and limitations of an analytics-based product planning approach.
\end{abstract}

Keywords- Software product management; product planning; analytics; decision-making; SaaS

\section{INTRODUCTION}

Cloud computing is changing the software product business [1]. Companies started to abandon the paradigm of packaged products and deliver software as a service (SaaS). This shift in software technology affects product management [2] as it implies changes in the business models [1] and the way product releases are managed and delivered [3, 4]. Users pay monthly subscriptions to access to a software product that the supplier hosts and continuously evolves and improves.

While packaged software is released relatively infrequently, publishers of SaaS tend to release new features as soon as they are completed [5] due to easier updating of the software and its compatibility for all users at the same time. Also, agile development practices encourage such change in release behavior. The frequent releases increase the importance of product planning and of product and market analysis [2]. The plans used to steer development need to be continuously updated and the attractiveness and the impact of the implemented features on product business and use monitored $[6,7]$.

For planning the development and evolution of a software product, a product manager consults selected customers, partners, consultants, and company-internal stakeholders [8-10]. Consultation of such intermediaries to markets limits the quality of information that can be obtained. Power, opinions, and personal interests bias these inputs [11]. As a result, the product manager has difficulties in assessing whether the chosen features encourage the customers to buy subscriptions and the users to use the product in a way that is representative for the markets.

Analytics have been used to address the bias problem of stakeholder consultation. They provide measurements that are not affected by power and politics for guiding sales and marketing [12], for informing usability, reliability, and quality of service engineering [13, 14], and to support quality assurance. Despite their importance, analytics have not been used yet for guiding product planning. It is unclear whether and how analytics can be used to evaluate and prioritize the development and evolution of product features and which SaaS analytics should be used for that purpose.

This paper investigates opinions of experienced product managers regarding the use of analytics for product planning. It focuses hereby on SaaS-enabled analytics that are collected from user-software interaction. It excludes other analytics such as those collected about the product business by the executive staff in a company [15] or by an e-commerce platform [16]. The results of 17 in-depth interviews were analyzed with quantitative and qualitative techniques to identify how analytics should be used for product planning and what the strengths and limitations of an analytics-based product planning approach are.

The remainder of the paper is structured as follows. Section II reviews related work to develop taxonomies of product planning decisions and of SaaS analytics. Section III describes the empirical research methodology. Section IV analyzes the results of the in-depth interviews. Section $\mathrm{V}$ discusses these results. Section VI concludes. 


\section{RELATED WORK}

Product planning is concerned with defining what a software product will be and how it will evolve [2]. Product planning decisions are taken at four levels in a company's product portfolio [8]. Portfolios are managed at the level of the company or business unit [17]. Roadmaps that capture long-term plans for product evolution [18]. Release plans are used to scope development projects [10]. Requirements specify ideas and needs [19].

Product planning involves creation, change, deletion, and allocation decisions. At the portfolio level, these decisions concern products. At the roadmap level they concern features these products consist of. At the release level they concern the requirements that the features contain. Prioritization of such products, features, and requirements and technology selection supports such decision-making. Table I gives and overview of decisions that are reported in work about product management.

TABLE I. TAXONOMY OF PRODUCT PLANNING DECISIONS

\begin{tabular}{|c|c|c|}
\hline Level & Decision & References \\
\hline \multirow{3}{*}{ Portfolio } & Create a new product & {$[20-22]$} \\
\hline & Remove an old product & {$[20]$} \\
\hline & $\begin{array}{l}\text { Select technology for } \\
\text { developing a product }\end{array}$ & {$[21]$} \\
\hline \multirow{7}{*}{ Roadmap } & $\begin{array}{l}\text { Create a new feature for } \\
\text { the current product }\end{array}$ & [23] \\
\hline & $\begin{array}{l}\text { Remove a feature from } \\
\text { the current product }\end{array}$ & {$[24]$} \\
\hline & $\begin{array}{l}\text { Enhance a feature(s) in } \\
\text { the current product }\end{array}$ & {$[20]$} \\
\hline & $\begin{array}{l}\text { Prioritize features in the } \\
\text { current product }\end{array}$ & {$[23,25-27]$} \\
\hline & Allocate resources & {$[23,26-29]$} \\
\hline & $\begin{array}{lll}\begin{array}{l}\text { Allocate } \\
\text { releases }\end{array} & \text { features } & \text { to } \\
\end{array}$ & {$[23,25-28,30]$} \\
\hline & $\begin{array}{l}\text { Select technology for } \\
\text { developing a feature(s) }\end{array}$ & {$[23,26,28,29,31]$} \\
\hline \multirow{7}{*}{ Release } & $\begin{array}{l}\text { Create new requirements } \\
\text { for a feature(s) }\end{array}$ & {$[8,32-37]$} \\
\hline & $\begin{array}{l}\text { Change a requirement(s) } \\
\text { in a feature }\end{array}$ & {$[28,32,37]$} \\
\hline & $\begin{array}{l}\text { Remove a requirement } \\
\text { from a feature }(\mathrm{s})\end{array}$ & {$[38]$} \\
\hline & Prioritize requirements & {$[8,28,36,39,40]$} \\
\hline & Allocate resources & {$[32-34,38,39,41]$} \\
\hline & $\begin{array}{l}\text { Allocate requirements to } \\
\text { releases }\end{array}$ & {$[8,28,33-36,39,40,42]$} \\
\hline & $\begin{array}{l}\text { Select technology for set } \\
\text { of requirements }\end{array}$ & [34] \\
\hline
\end{tabular}

None of the product planning approaches refers to analytics as a potential input to product planning. Analytics, however, provide essential data for guiding sales, marketing, and engineering of usability, performance, reliability, and quality of service. In these contexts, analytics are a source of measurements for understanding customer, user, and product behavior. Statistical analysis and data mining give insights into patterns and trends in the analytical data that are used to guide business and engineering decisions.

Analytics are a data-centric style of decision making [43]. They consist of measurements that generate data and the transformation of these data into indicators for decision-support. For web applications, a large variety of measurements have been proposed that can be obtained with analytics [12, 13, 44-53]. Tools like Google analytics, Piwik, Yahoo Web Analytics, Stat Counter, New Relic, and Woopra hook into web-based applications, perform the measurements, and transform the data to provide indicators for decision-making.

Analytics literature conceptualizes a web application as a product that consists of pages that are accessed with different usage patterns by users from diverse usage sources. Analytics measure attributes of these conceptual elements and of product healthiness. Table II provides an overview of attributes that are measured with such webbased analytics.

TABLE II. TAXONOMY OF MEASUREMENTS FOR WEB APPLICATIONS.

\begin{tabular}{|c|c|}
\hline Measured Object & Measured Attributes \\
\hline Product & $\begin{array}{l}\text { Product use } \\
\text { Number of users } \\
\text { Duration of using the product } \\
\text { Time between visits } \\
\text { New users } \\
\text { Returning users }\end{array}$ \\
\hline Page & $\begin{array}{l}\text { Page use } \\
\text { Number of users } \\
\text { Duration of using a feature } \\
\text { Entrance page } \\
\text { Exit page } \\
\text { Bounce }\end{array}$ \\
\hline Usage pattern & $\begin{array}{l}\text { Click activity } \\
\text { Depth of use } \\
\text { Click stream/path }\end{array}$ \\
\hline Usage source & $\begin{array}{l}\text { Referrers } \\
\text { Location/ISP per use } \\
\text { Search engines and keywords } \\
\text { Campaigns }\end{array}$ \\
\hline $\begin{array}{l}\text { Technologies and } \\
\text { channels used to } \\
\text { access the product }\end{array}$ & $\begin{array}{l}\text { Languages } \\
\text { Browsers } \\
\text { Operating Systems } \\
\text { Plugins } \\
\text { Screen resolution }\end{array}$ \\
\hline Product health & $\begin{array}{l}\text { Errors } \\
\text { Downtime } \\
\text { Response time } \\
\text { Throughput } \\
\text { DOS attack } \\
\text { Worm attacks }\end{array}$ \\
\hline
\end{tabular}

Analytics are used for informing usability, reliability, and quality of service engineering decisions. In usability engineering data about page use frequency, users, click paths, and events are stored in web-log files and combined with user feedback [13, 54]. These measurements are usually collected during user testing or after a release. The data is used to evaluate the acceptance of a solution for given classes of users. One of the established methods used 
for analytics-based usability engineering is A/B testing, which allows comparing the attractiveness of two alternative designs [55].

In reliability engineering data about product availability, probability of fail and fail safe are used for both software and hardware $[46,56]$. These measurements are usually collected during the entire product life cycle, including planning, development, test, manufacturing, operation and maintenance. The data is used to cope with the probability of failure of features, components and product and is known as the heart of risk analysis and quality assurance. Reliability engineering depends on probabilistic methods such Fault tree to predict whether the reliability is fulfilled.

In Quality of Service (QoS) analytics measure availability, duration, performance, security, response time and throughput [48, 49]. These measurements are usually collected during and after release and widely drawn attention in network, multimedia, distributed and real time products $[57,58]$. The data is used to ensuring high-quality combination of multiple quality attributes. The QoS approaches such as QoS computation model address different perspectives of quality attributes and domain specific criteria [49]. Also, QoS supports performance engineering by analytics of workload intensities, delay, loss ratio and throughput to assure meeting performance objectives in all software engineering activities and analyses [47, 58].

The needs of product planning for analytics overlap, but differ in some important aspects from other web engineering domains. Product managers conceptualize a product to consist of features rather than pages [8]. Features are often collection of use cases or refer to product quality attributes that cut across pages. Product managers are interested in insights about customer preferences and how features can be bundled in a product to create business value and sustain customer loyalty [7]. How product managers would use analytics, however, has not been established yet and is subject of the here presented research.

\section{RESEARCH METHOLOGY}

We used empirical survey methodology [59] based on in-depth interviews with experienced SaaS product managers to explore how analytics can support planning of SaaS development and evolution. The objectives of the study were twofold. First we wanted to understand how product managers would use the measurements for web applications shown in Table II (pages replaced by features) for those decisions shown in Table I they deem most important. Second, we wanted to understand what the strengths and limitations of analytics for product planning are.

To achieve these objectives, we formulated the following research questions. RQ1: what decisions are taken for planning SaaS products? RQ2: what are the most relevant SaaS analytics to support the product planning decisions? RQ3: what are the strengths and limitations of an analytics-based product planning approach?

\section{A. Research design}

We used a purposive stratified sampling approach to recruit interviewees. It was selected against the experiment alternative, which was dismissed due to factual information needs from different groups of practitioners (the more the best) to generalize the results. We asked a well-established software product management consultancy company to identify experienced SaaS product managers in a wide variety of SaaS contexts. 17 interviewees were identified from 3 micro, 4 small, 7 medium, and 3 large companies who managed 6 new respectively 11 already existing software products. All interviews were structured alike and were performed with European product managers. High saturation of the interview results can be obtained with this number of interviews, similarity of interview questions, and homogeneity of interviewees [60].

We structured the in-depth interviews with the SaaS product managers with a questionnaire. The interview started with questions about the interviewee and the organization. The product planning theme formed the core of interview. First questions were asked about the most successful product that the interviewee had planned, what planning decisions were taken (Table I), and how these decisions were taken. Secondly, relevance of the SaaS analytics for that decision-making was elicited by asking the interviewee to rank the importance of the analytic objects and attributes to be measured (Table II). The interview ended with open ended questions about strengths and limitations of an analytics-based product planning approach.

Data was collected with telephone interviews. To avoid disadvantages of telephone interview related to lack of visual material and avoid less complexity, the screen of interviewer's computer was shared. It presented the questionnaire and allowed the interviewee to rank the analytic objects and attributes. The rankings were stored in a database. The interviews were recorded and the discussions of analytics strengths and limitations transcribed.

RQ1 and RQ2 were answered by analyzing demographic and ranking data quantitatively. Descriptive statistics were used to describe product planning behavior and satisfaction and analytics relevance. The nonparametric Kruskal-Wallis test was used to test whether decision and analytics types interact with each other or are independent. A non-parametric test was used because the Kolmogorov-Smirnov test showed that the ranking data was not distributed normally.

RQ3 was answered by analyzing the answers about strengths and limitations of analytics qualitatively. Conventional content analysis was used [61]. The codes for arguments in favor and against analytics for product 
planning were derived in a bottom-up fashion from the empirical data.

\section{B. Validity threats}

Conclusion, internal, construct, and external validity are key threats to validity in the fixed-design research we used to answer RQ1 and RQ2 [62].

Most important was conclusion validity. 17 answers is a small number of samples, hence limit the statistical power. The combination with qualitative analysis for understanding how and why product managers would use analytics contained the impact of this threat. A second problem of the research is that opinions of product managers about analytics were elicited rather than experiences of using these analytics. This problem was unavoidable as no tool could be identified that measured features instead of pages. Hence complete-enough experience in using SaaS analytics for product planning did not exist. The anchoring of the interviews on a concrete product planning experience reduced this threat somewhat. Experience-based studies should be performed when adapted tool support is available.

The internal validity threat was small. The interview design ensured that the product managers discussed the effects of analytics on product planning decisions only. In addition, the statistical analysis was combined with qualitative analysis for understanding how and why analytics are deemed relevant for product planning.

Construct validity concerned the understanding of product planning and analytics. Experience of the product manager in managing SaaS products, the anchoring of each interview in a concrete planning experience of the product manager, explanation of what is meant with each type of analytics, and the possibility of clarifying uncertainties during the interview contained this threat.

External validity concerns the ability to generalize the results. Again, 17 answers are a small number of samples. However, the stratified sampling ensured that the results represent a rich variety of SaaS product management situations. In addition, the study was angled on SaaS, but the results may be applicable for other types of software products. For example, self-updating applications blur the boundaries between packaged and cloud software. Largescale surveys should be performed to corroborate the results of this study.

Reactivity, researcher bias, and respondent bias are key threats to validity in the qualitative research we used to answer RQ3 [63]. Our interaction with the interviewees was short, giving us no possibility to affect their work. Hence, the reactivity threat was small. To contain researcher bias, we used observer triangulation and member checking. The interviews were performed by alternating pairs of researchers. This allowed reducing the influence of a single researcher, while facilitating consistency of results. The collected data and the analysis results were shared with the interviewees to check for correctness. The interviewing of 17 product managers, identified with stratified sampling, and the combination of quantitative and qualitative analysis reduced the influence of respondent bias.

\section{ANALYSIS AND RESUlTS}

\section{A. The effect of SaaS-based analytics on product planning decisions}

Demographic results about interviewees illustrate the distribution of answers from different perspectives of product, people, and organization. Respondents were 14 product managers $(82 \%), 2$ chief technology officers $(12 \%)$, and 1 chief executive officers $(6 \%)$ with average of $7.5,9$, and 12 years of experience respectively. These results reflect the professional's ideas in product planning with different experience. If the interviewees had product managing experience, product manager role was assigned to them, otherwise other higher roles were considered.

Through the interview, it was asked from interviewees to consider a product, which they have planned and are most satisfied with. The distribution of responses for product type shows $41.2 \%$ of Consumer-Oriented-Software, $29.4 \%$ business oriented, and $29.4 \%$ information displayand-transaction-entry.

All the interviewees selected roadmapping with features as the type of decision making they were involved most, and then answered about importance of analytics involvement for two decisions. To analyze the relation between product planning decisions and category of analytics, data for analytics-category were grouped based on decision types and normality was checked inside each group using Kolmogorov-Smirnov test. For all groups in the test, results were significant (Lower than or equal to $0.05)$ which means the data was not normally distributed.

For analyzing multiple categories, methods such as chi-squared, fisher's exact and Anova tests are common. However, our data involved more than 2 groups of samples that were not shaped normally. For that reason we selected the Kruskal-Wallis test. The test was used for testing the H0 hypothesis with categorical analysis by detecting the difference between more than two independent groups of samples.

H0: There is no difference between each analyticscategory value for different product planning decisions.

This hypothesis includes sub-hypothesis related to each analytics category. According to TABLE III, since pvalues with the common confidence level of $95 \%$ for all analytics-categories were more than 0.05 , there was no significance to reject all sub-hypothesis and thus the H0 was not rejected as well. So, it concludes that analyticscategory distributions functions are not different for different planning-decisions. 
TABLE III. KRUSHKAL-WALLIS TEST FOR CATEGORY OF ANALYTICS GROUPED BY PRODUCT PLANNING DECISIONS

\begin{tabular}{|c|c|c|c|c|c|c|}
\hline & Product & Feature & $\begin{array}{c}\text { Usage } \\
\text { pattern }\end{array}$ & $\begin{array}{c}\text { Usage } \\
\text { source }\end{array}$ & $\begin{array}{c}\text { Technologies } \\
\text { and channels }\end{array}$ & $\begin{array}{c}\text { Product } \\
\text { health }\end{array}$ \\
\hline $\begin{array}{c}\text { Chi- } \\
\text { Square }\end{array}$ & 1.047 & 2.487 & 3.355 & 7.347 & 4.871 & 3.109 \\
df & 5 & 5 & 5 & 5 & 5 & 5 \\
p & .959 & .778 & .645 & .196 & .432 & .683 \\
\hline
\end{tabular}

Through the interviews, interviewees were questioned about their arguments for particular answers. The results from content analysis of these arguments show that the following factors can affect on importance level of one analytic: Number of product's users, customer type, required quality level, maturity of the product and organizational goal about the product (i.e. customercentric, user satisfaction-centric, focus group-centric, or market-centric).

In the interviews, the main reasons of analytics importance were related to understanding the product's usability (such as understanding user's behaviors, ease of use and feature's popularities) and problem handlings in early stages. Interviews presented that analytics might not be important for discussion about development technologies while they are useful for client's technologies. Also, the interviewees confirmed that receiving customer and end-users feedback can directly or through survey forms help product managers to take better decisions.

\section{B. The importance of analytics for product planning}

As there were not significant differences between categories of analytics for product planning decisions, a descriptive analysis conducted for analytics-category regardless of the decision type.

Results showed that $61.8 \%$ of the responses have been selected as "very important" for "Product value", 58.8\% for "Feature value" and $64.7 \%$ for "Product healthiness" categories. For "Referral sources" category, $61.8 \%$ of responses have been chosen as "not important". Categories of "Technologies and channels" and "Usage pattern" have been rated majorly "important" regarding $47.1 \%$ and $32.4 \%$ of the corresponding responses. Importance of analytics-categories were valued from 0 to 4 that implicate "no idea", "not important", "less important", "important", and "very important" respectively.

TABLE IV shows the statistics of analytics-categories including number of samples $(\mathrm{N})$, mean value for each category (mean), variance (Var.), minimum value (Min), Maximum value (Max) and confidence intervals (Conf.) with the common confidence level of $95 \%$ that has been calculated using T-test distribution.
TABLE IV. ANALAYTICS-CATEGORY STATISTICS

\begin{tabular}{|r|r|r|r|r|r|r|}
\hline & Product & Feature & $\begin{array}{c}\text { Usage } \\
\text { pattern }\end{array}$ & $\begin{array}{c}\text { Usage } \\
\text { sources }\end{array}$ & $\begin{array}{c}\text { Technologies } \\
\text { and channels }\end{array}$ & $\begin{array}{c}\text { Product } \\
\text { health }\end{array}$ \\
\hline $\mathrm{N}$ & 34 & 33 & 34 & 31 & 32 & 30 \\
Mean & 3.44 & 3.52 & 3.12 & 1.48 & 2.43 & 3.59 \\
Var. & .739 & .508 & .713 & .725 & .944 & .507 \\
Conf. & \pm 0.30 & \pm 0.25 & \pm 0.29 & \pm 0.31 & \pm 0.36 & \pm 0.26 \\
Min & 1 & 1 & 1 & 1 & 1 & 1 \\
Max & 4 & 4 & 4 & 4 & 4 & 4 \\
\hline
\end{tabular}

In this study the analytics importance for product planning was measured as well. In the interview, analytics were ranked inside the related categories. To achieve analytics values across all categories, they were calculated and scaled between 0 and 1, based on the frequencies of rates for each analytic in the corresponding category (e.g. $66.7 \%$ of respondents have ranked "Statistics about product use" analytic as the highest level) and the value of analytics-category. The Figure 1 illustrates the analytic value by a descending order, which means that analytics at the top levels of the figure are weighted as the important ones. For each analytic, confidence interval (with the common confidence level of $95 \%$ ) was also calculated using T-test distribution to identify a range of possible analytic values. Minimum and maximum values are presented as the top and bottom bars of the main analytic value in Figure 1.

\section{Strength and limitations of an analytics-based product planning approach}

The analytics-based product planninng, is a approach that considers analytics as well as other influential factors for taking a planning decision. According to the interviewees, the approach has a strength: of shifting the mode of product planning decisions from the intuitionbased mode to a more data-driven mode by collecting the analytics and reflecting them in taking the influenced decisions. The qualitative analysis of interviewees' argumentations reveals strengths and limitation of analytical approach for product planning:

Analytics increases a product manager's knowledge about Usability. It is important to understand the product usability, especially in understanding the user behavior, ease of use, and identifying popular features. Also analytics improve learnability of different usage patterns, which can increase decision-making quality in general. Analytics improves problem handling as well. Users won't accept faulty product. Analytics helps to identify problems as soon as possible and devise a replacement in the time of failure. Improve handling the client-side technologies are done by the analytics as well. 


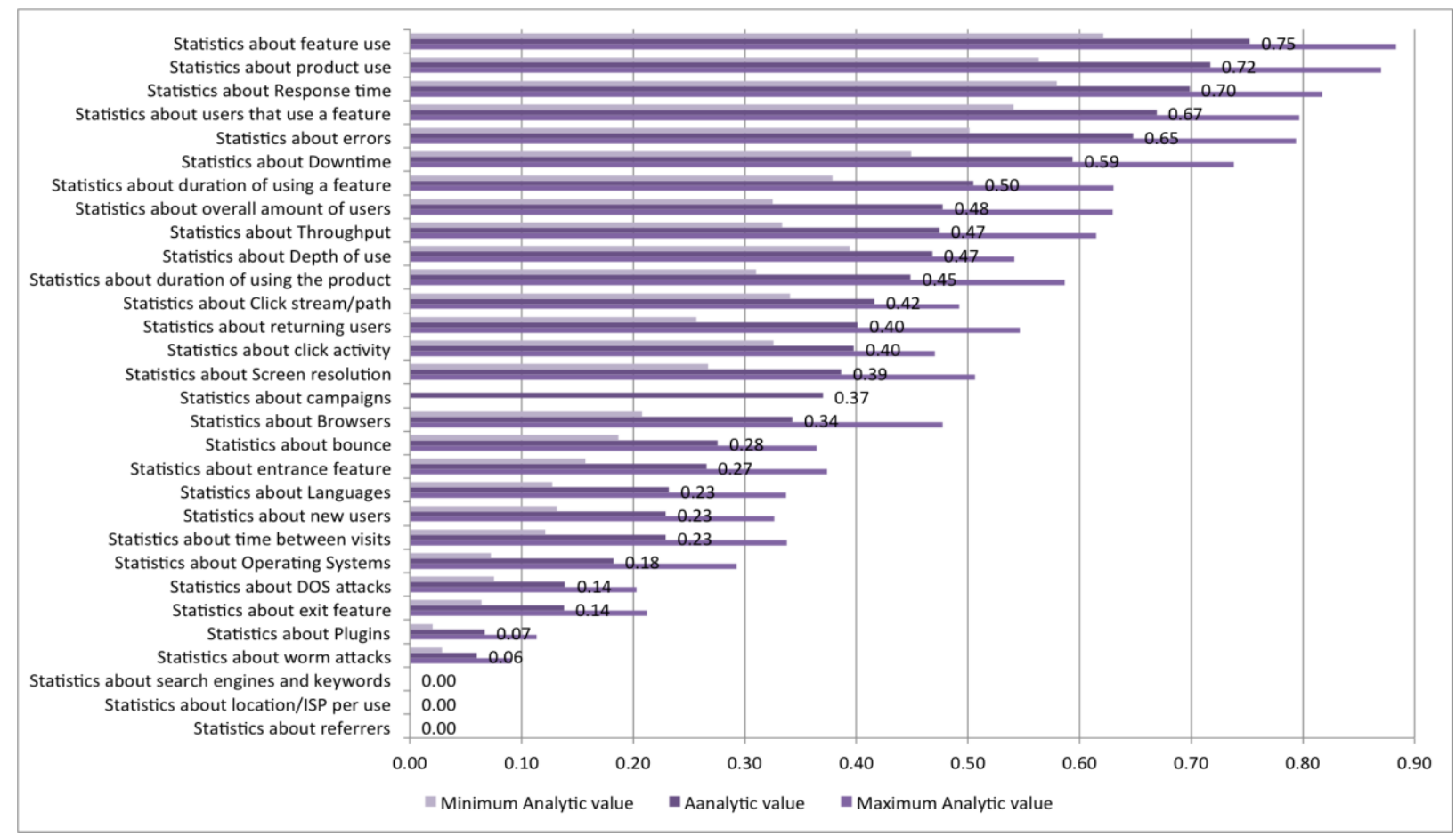

Figure 1. Analytics values

The limitations of using analytics address the limitation in receiving customer feedback and end-user feedback. The feedback can be received directly or through survey forms, help to take better decisions, which cannot be replaced by analytics. The next limitation indicates that for an immature product, analytics is not so much helpful. Within the first release of a product, when a product is hardly mature, data collected through measurements cannot help decision making so much. But after a release or providing a prototype those analytics can be important. Analytics is not important for the development technology aspect. Technology has two aspects in planning a SaaS-based product. One aspect is related to the technology that should be considered for product development, and the other one is the technology that is required in client side for running a product. For finding development technologies analytics is not important but after the release of the technology, product popularity is monitored to find the effect of implementing the technology on planning.

Another limitation is about finding the right analytics and the right tool, and interpreting the observed data. It is important to collect right analytics related to a feature through a suitable tool. To interpret analytics, the measurements need to be combined with observations about external factors such as environmental, seasonal, economic, and political factors, which all can have some difficulties.

For some product features the analytics are clear and simple, however there might be features that require contemplation and extra time. Sometimes, it might be required to mix analytics and consider them in more details. Some planning decisions such as "allocating resources" cannot be supported by analytics, as related analytics were not included in the taxonomy.

\section{DISCUSSION}

From the three levels of product planning decisions shown in Table I, roadmapping was most popular among the product managers who participated in the study. Within roadmapping, the study results show that the relevance of analytics-categories did not differ between different types of roadmapping decisions. Most important was measurement of the objects product, feature, and product health. These results are consistent with recommendations for engineering quality of service [13] and are important for sustaining customer loyalty [7].

Product health analytics are central for reliability engineering [46], quality of service [48, 58], and performance engineering [47]. As the study was angled from a product planning perspective, the obtained results confirm the importance of analytics for product management beyond product launch support [64] and product validation [14].

The study results show that measurement of "product use", "feature use", "users of features", "response time", "product errors", and "downtime" were perceived by product managers to be most important for product planning. These results are roughly in line with judgments of all-over-the-board SaaS analytics importance [12]. They show, however, that relating the amount of product and feature use to the product's users are more important for 
product planning than usage patterns and user productivity, which would be important for usability engineering.

The relevance of analytics type is determined by factors other than the type of planning decisions. Instead, product maturity and product goals were factors that affect the importance of different analytics types. Such situational factors are also relevant for judging the importance of product management practices [65].

Within the first release of a product, when a product is hardly mature, the analytics cannot help much in decision making unless a prototype is developed. This is also applicable for new features. The easy upgrading characteristic of the SaaS delivery model facilitates a shorter release of the feature prototype, helping to evaluate the impact of increased feature maturity. Therefore, smaller releases and faster releases can be part of a product manager's strategy to collect evidence for planning software evolution.

To specify features attractiveness, when planning software products without analytics, stakeholders assign numbers to features that reflect the estimated impact of these features [41, 66]. Analytics support such estimation with real-world data about feature use. Marketing and sales, in the context of electronic commerce, has a tradition of using such analytics for customer acquisition and retention [44]. Analytics that would correspond to such marketer use would be "product value", "feature value", and "usage patterns". These preferences for analytics are consistent with a SaaS product manager's needs, except that a product health is more important for product planning than usage patterns.

Many SaaS analytics solutions are present on the market, including Google Analytics, APIGee, MixPanel, and Mashery. Some of the present solutions try to connect analytics with business value, however do not explain how the analytics should be used for planning and evolving SaaS products. The presented results fill the gap by showing preferences for analytics for product planning. These preferences are heuristics that help identify concrete cases and examples of how analytics actually support product planning decisions.

Sometimes only a single measurement might provide uncertainties about right interpretations. For example high usage of a feature is ambiguous because it might indicate the attractiveness of the feature or an implementation of the feature that is difficult to use. This problem can be addressed by including more measurements. The more measurements are applied for analyzing a feature to support a planning decision, the smaller the likelihood of misinterpretation of the measurements is.

Although analytics support decision-making, our obtained results showed that customer or end-users feedbacks, directly or through survey forms, is needed for taking good decisions. These feedback provide qualitative data that allows interpreting the analytics [13].

\section{CONCLUSIONS}

SaaS analytics represent a new source of information for product managers to support product planning. The study showed that SaaS product managers benefit most by using analytics for planning which product features to develop or evolve. The study has important implications for the product management and the analytics communities. Analytics are a relevant new information source for reducing bias in product-related decisionmaking. The analytics allow grounding the decisions on evidence, hence limit the influence of power and politics. Statistics about feature and product use, about the users, and about errors and downtime were perceived to be the most relevant analytics. The analytics about feature health were expected to inform quality improvement decisions and constrained the value of the usage-related analytics to inform about feature attractiveness.

For analytics to become effective for product planning, tool suppliers need to shift their attention from monitoring of web pages to monitoring features. Such change will be valuable as many features cut across multiple pages and many pages integrate parts of multiple features.

There are still rooms for strengthening the research finding. The scope of this study was limited to investigating the effect of analytics on roadmap planning. One recommendation for future is to extend this research and support the effect of analytics on portfolio management and release planning as well. The study has proved importance of analytics for taking a decision about a feature but didn't specified which types of measurements suit each feature. Future research needs to identify solutions for measuring cross-cutting features and further corroborate the use of analytics for product planning.

\section{ACKNOWLEDGMENTS}

This work is part of the BESQ+ research project funded by the Knowledge Foundation (grant: 20100311) in Sweden.

\section{REFERENCES}

1. Cusumano, M.A., The changing software business: Moving from products to services. Computer, 2008. 41(1): p. 20-27.

2. Fricker, S., Software Product Management, in Software for People: Fundamentals, Trends and Best Practices, A. Maedche, A. Botzenhardt, and L. Neer, Editors. 2012, Springer. p. 53-81.

3. Leavitt, N., Is Cloud Computing Really Ready for Prime Time? IEEE Computer, 2009. 42(1): p. 15-20.

4. Erdogmus, H., Cloud Computing: Doeas Nirvana Hide behind the Nebula? IEEE Software, 2009. 26(2): p. 4-6.

5. Coudhary, V., Software as a Service: Implications for Investment in Software Development, in 40th Hawaii International Conference on System Sciences. 2007: Hawaii, USA. 
6. Vlaanderen, K., et al., The Agile Requirements Refinery: Applying SCRUM Principles to Software Product Management. Information and Software Technology, 2011. 53(1): p. 58-70.

7. Kittlaus, H.-B. and P. Clough, Software Product Management and Pricing. 2009: Springer.

8. van de Weerd, I., et al., Towards a Reference Framework for Software Product Management, in 14th IEEE International Requirements Engineering Conference (RE'06). 2006: Minneapolis; MN, USA.

9. Barney, S., A. Aurum, and C. Wohlin, A product management challenge: Creating software product value through requirements selection. Journal of Systems Architecture, 2008. 54(6): p. 576-593.

10. Svahnberg, M., et al., A Systematic Review on Strategic Release Planning Models. Information and Software Technology, 2010. 52(3): p. 237-248.

11. Milne, A. and N. Maiden, Power and Politics in Requirements Engineering: Embracing the Dark Side? Requirements Engineering, 2012. 17(2): p. 83-98.

12. Croll, A. and S. Power, Complete web monitoring. 2009: O'Reilly Media.

13. Kuniavsky, M., Observing the user experience: a practitioner's guide to user research. 2003: Morgan kaufmann.

14. Lee, J.Y., J.W. Lee, and S.D. Kim, A quality model for evaluating software-as-a-service in cloud computing, in Software Engineering Research, Management and Applications, 2009. SERA'09. 7th ACIS International Conference on. 2009. p. 261-266.

15. Shung, K.P. and M.C. Junyu, Application of Analytics in Business Strategy. Business Intelligence Journal, 2012. 5(1).

16. Kohavi, R., N.J. Rothleder, and E. Simoudis, Emerging trends in business analytics. Communications of the ACM, 2002. 45(8): p. 45-48.

17. Cooper, R., S. Edgett, and E. Kleinschmidt, New Product Portfolio Management: Practices and Performance. Journal of Product Innovation Management, 1999. 16(4): p. 333-351.

18. Phaal, R., C. Farrukh, and D. Probert, Strategic Roadmapping: A Workshop-Based Approach for Identifying and Exploring Strategic Issues and Opportunities. Engineering Management Journal, 2007. 19(1): p. 3-12.

19. Gorschek, T. and C. Wohlin, Requirements Abstraction Model. Requirements Engineering, 2006. 11(1): p. 79101.

20. Ebert, C., The impacts of software product management. Journal of systems and software, 2007. 80(6): p. 850-861.

21. Muller, G., Roadmapping. 1999, Philips Research: Eindhoven, The Netherlands.

22. Jiao, J. and Y. Zhang, Product portfolio planning with customer-engineering interaction. Iie Transactions, 2005. 37(9): p. 801-814.
23. Saliu, O. and G. Ruhe, Supporting software release planning decisions for evolving systems, in Software Engineering Workshop, 2005. 29th Annual IEEE/NASA. 2005. p. 14-26.

24. Bjarnason, E., K. Wnuk, and B. Regnell, Overscoping: Reasons and consequences-A case study on decision making in software product management, in Software Product Management (IWSPM), 2010 Fourth International Workshop on. 2010. p. 30-39.

25. Ngo-The, A. and G. Ruhe, A systematic approach for solving the wicked problem of software release planning. Soft Computing-A Fusion of Foundations, Methodologies and Applications, 2008. 12(1): p. 95108.

26. Tang, A., T. Boer, and H. Vlient, Building roadmaps: a knowledge sharing perspective, in Sixth Workshop SHAring and Reusing architectural Knowledge, Hawaii. 2011.

27. Heikkila, V., et al., Rigorous support for flexible planning of product releases-a stakeholder-centric approach and its initial evaluation, in System Sciences (HICSS), 2010 43rd Hawaii International Conference on. 2010. p. 1-10.

28. Fricker, S. and S. Schumacher, Release Planning with Feature Trees: Industrial Case, in Requirements Engineering: Foundations for Software Quality (RefsQ 2012). 2012: Essen, Germany.

29. Vähäniitty, J., C. Lassenius, and K. Rautiainen, An Approach to Product Roadmapping in Small Software Product Businesses, in 7th International Conference on Software Quality (ECSQ 2002). 2002: Helsinki, Finland.

30. Garcia, M.L. and O.H. Bray, Fundamentals of technology roadmapping. Sandia Nat. Laboratories, Albuquerque, New Mexico, 1997.

31. Lee, S., et al., Technology Roadmapping for $R \& D$ planning: The case of the Korean parts and materials industry. Technovation, 2007. 27(8): p. 433-445.

32. Regnell, B., L. Karlsson, and M. Höst, An analytical model for requirements selection quality evaluation in product software development, in Requirements Engineering Conference, 2003. Proceedings. 11th IEEE International. 2003. p. 254-263.

33. Al-Emran, A. and D. Pfahl, Operational planning, replanning and risk analysis for software releases. Product-Focused Software Process Improvement, 2007: p. 315-329.

34. Karlsson, L. and B. Regnell, Introducing tool support for retrospective analysis of release planning decisions. Product-Focused Software Process Improvement, 2006: p. 19-33.

35. Momoh, J. and G. Ruhe, Release planning process improvement-an industrial case study. Software Process: Improvement and Practice, 2006. 11(3): p. 295-307. 
36. van de Weerd, I., W. Bekkers, and S. Brinkkemper, Developing a maturity matrix for software product management. Software Business, 2010: p. 76-89.

37. Wnuk, K., R.B. Svensson, and B. Regnell, Investigating Upstream versus Downstream Decision-Making in Software Product Management, in Software Product Management (IWSPM), 2009 Third International Workshop on. 2009. p. 23-26.

38. Regnell, B. and K. Kuchcinski, Exploring Software Product Management decision problems with constraint solving-opportunities for prioritization and release planning, in Software Product Management (IWSPM), 2011 Fifth International Workshop on. 2011. p. 47-56.

39. AlBourae, T., G. Ruhe, and M. Moussavi, Lightweight replanning of software product releases, in Software Product Management, 2006. IWSPM'06. International Workshop on. 2006. p. 27-34.

40. Benestad, H.C. and J.E. Hannay, A comparison of model-based and judgment-based release planning in incremental software projects, in Proceedings of the $33 r d$ International Conference on Software Engineering. 2011. p. 766-775.

41. Ruhe, G. and M.O. Saliu, The Art and Science of Software Release Planning. IEEE Software, 2005. 22(6): p. 47-53.

42. Du, G., J. McElroy, and G. Ruhe, Ad hoc versus systematic planning of software releases-a three-staged experiment. Product-Focused Software Process Improvement, 2006: p. 435-440.

43. Buse, R. and T. Zimmermann, Analytics for Software Development, in FSE/SDP Workshop on Future of Software Engineering Research (FoSER'10). 2010: Santa Fe, New Mexico, USA.

44. Peterson, E.T., Web analytics demystified: a marketer's guide to understanding how your web site affects your business. 2004: Celilo Group Media.

45. Kaushik, A., Web Analytics: An Hour A Day. 2007, Indianapolia, Indiana, USA: Wiley Publishing Inc.

46. Houtermans, M., T.V. Capelle, and M. Al-Ghumgham, Reliability Engineering \& Data Collection, in Systems, 2007. ICONS'07. Second International Conference on. 2007. p. 42-42.

47. Woodside, M., G. Franks, and D.C. Petriu, The Future of Software Performance Engineering, in Future of Software Engineering, 2007. FOSE '07. 2007. p. 171 187.

48. Menasce, D.A., QoS issues in Web services. Internet Computing, IEEE, 2002. 6(6): p. 72-75.

49. Liu, Y., A.H. Ngu, and L.Z. Zeng, QoS computation and policing in dynamic web service selection, in Proceedings of the 13th international World Wide Web conference on Alternate track papers \& posters. 2004. p. 66-73.

50. Bose, R., Advanced analytics: opportunities and challenges. Industrial Management \& Data Systems, 2009. 109(2): p. 155-172.

51. Kaushik, A., Web analytics 2.0: the art of online accountability \& science of customer centricity. 2009: Sybex.

52. Clifton, B., Advanced web metrics with Google Analytics. 2012: Sybex.

53. Burby, J. and S. Atchison, Actionable Web Analytics. Sybex, Indianapolis, 2007.

54. Holzinger, A., Usability engineering methods for software developers. Communications of the ACM, 2005. 48(1): p. 71-74.

55. Dixon, E., E. Enos, and S. Brodmerkle, A/B Testing. 2011.

56. Banerjee, S., H. Srikanth, and B. Cukic, Log-based reliability analysis of software as a service (saas), in Software Reliability Engineering (ISSRE), 2010 IEEE 21 st International Symposium on. 2010. p. 239-248.

57. Rajkumar, R., et al., A resource allocation model for QoS management, in Real-Time Systems Symposium, 1997. Proceedings., The 18th IEEE. 1997. p. 298-307.

58. Shaikh, J., M. Fiedler, and D. Collange, Quality of Experience from user and network perspectives. Annals of Telecommunication, 2010. 65: p. 47-57.

59. Rea, L. and R. Parker, Designing and Conducting Survey Research: A Comprehensive Guide. 3rd ed. 2005, San Francisco, CA, USA: Jossey-Bass.

60. Guest, G., A. Bunce, and L. Johnson, How many interviews are enough? An experiment with data saturation and variability. Field methods, 2006. 18(1): p. 59-82.

61. Hsieh, H.F. and S.E. Shannon, Three approaches to qualitative content analysis. Qualitative health research, 2005. 15(9): p. 1277-1288.

62. Wohlin, C., et al., Experimentation in software engineering: an introduction. 2000.

63. Robson, C., Real World Research: A Resource for Social Scientists and Practitioner Researchers. 2nd ed. 2002: Blackwell Publishing.

64. Soni, A. and H. Cohen, Successfully launching your product: getting it right. Handbook of Business Strategy, 2004. 5(1): p. 263-268.

65. Bekkers, W., et al., The influence of situational factors in software product management: an empirical study, in Software Product Management, 2008. IWSPM'08. Second International Workshop on. 2008. p. 41-48.

66. Nejmeh, B.A. and I. Thomas, Business-driven product planning using feature vectors and increments. Software, IEEE, 2002. 19(6): p. 34-42. 